\title{
The earliest cognitive change in a person with familial Alzheimer's disease: presymptomatic neuropsychological features in a pedigree with familial Alzheimer's disease confirmed at necropsy
}

\author{
S K Newman, E K Warrington, A M Kennedy, M N Rossor
}

\begin{abstract}
Comprehensive, longitudinal neuropsychological assessments are reported in a person "at risk" from autosomal dominant, necropsy confirmed familial Alzheimer's disease. The first assessment showed a moderately selective verbal memory deficit in the context of mild general intellectual impairment. Subsequent testing showed the progressive deterioration of visual memory and a mild decline of perceptual and spatial skills. Language and literacy skills, however, remained comparatively intact. The neuropsychological profiles obtained at each assessment are presented in profile maps. These permit direct longitudinal comparison of cognitive function, and may serve in the comparison of different potential cases of familial Alzheimer's disease. This case sought medical attention for memory difficulties 26 months after the first neuropsychological assessment. These results mark the first cognitive manifestations in a pedigree with familial Alzheimer's disease which, in this case, were seen presymptomatically. The findings are discussed in relation to neuropsychological studies of affected cases, and in terms of their reflecting the heterogeneous nature of familial Alzheimer's disease.
\end{abstract}

(F Neurol Neurosurg Psychiatry 1994;57:967-972)

for Neurology and

Neurosurgery, Queen

Square, London

WC1N 3BG, UK

$S \mathrm{~K}$ Newman

E K Warrington

A M Kennedy

M N Rossor

Neurology

Department,

St. Mary's Hospital,

Praed Street, London

W2 1PG, UK

$S \mathrm{~K}$ Newman

A M Kennedy

M N Rossor

Correspondence to:

Dr M N Rossor and

Professor EK Warrington,

The National Hospital

for Neurology

and Neurosurgery,

Queen Square, London

WCIN 3BG, UK

Received 29 March 1993 and in final revised form 28 October 1993.

Accepted 8 November 1993 of initially healthy elderly subjects with the chance of observing the early signs of Alzheimer's disease in a small proportion of them. The yield of information in comparison with the data collection is small and as a result such studies have tended to administer "dementia" scales rather than to attempt detailed neuropsychological testing to reduce assessment time. ${ }^{2}$

Autosomal dominantly inherited familial Alzheimer's disease provides a unique opportunity to document early cognitive changes in the affected patients because diagnosis can be made comparatively early in the disease process. Most reports on familial Alzheimer's disease, however, have focused on affected patients with a duration of symptoms of greater than two years. ${ }^{3-5}$ Swearer et $a l^{6}$ provide a detailed, neuropsychological account of the earliest reported features of familial Alzheimer's disease. In this group study, seven affected patients are reported from two early onset families. Two cases ( 1 and 7 ) were assessed only six months after clinical diagnosis. Case 7 performed within normal limits on a comprehensive neuropsychological battery (including tests of general intelligence, language and visuospatial functioning, attention, and problem solving skills and memory), although he was impaired on two tests of psychomotor speed and the digit symbol subtest of the WAIS-R. Case 1 showed impairments on these tests as well as on tests of delayed recall. The only other study of the early neuropsychological features of familial Alzheimer's disease reports similar results. ${ }^{7}$ The case described (subject III) comes from a pedigree with a mutation in codon 717 of the $\beta$-amyloid precursor protein gene (APP 717 valine-isoleucine) and had a one year history of progressive memory loss at the time of her first assessment. Once again, performance on a comprehensive neuropsychological battery was normal apart from her performance on two tests of recall and on one test of psychomotor speed. These deficits, in recall and cognitive processing speed, represent the earliest cognitive expression of Alzheimer's disease reported to date.

From the nature of the inheritance and the relatively constant ages at disease onset within families, ${ }^{8}$ asymptomatic, "at risk" subjects below the mean age at onset for the family can be examined. Such studies in Huntington's 
disease are well established and authors have documented both neuropsychological ${ }^{9}$ and motor abnormalities ${ }^{10}$ in apparently asymptomatic subjects. In publications on familial Alzheimer's disease to date, however, there are only two systematic studies of asymptomatic at risk subjects. ${ }^{11} 12$ In the first, positron emission tomography with 2-fluorodeoxyglucose showed a reduction in glucose metabolism in the supramarginal gyrus of an at risk case compared with normal controls. Neurological examination of this patient was reported to be normal although neuropsychological examination was not recorded. ${ }^{11}$ The second study involved neuropsychological assessment of 35 at risk subjects, with a wide age range (17-49 years) from two pedigrees with familial Alzheimer's disease confirmed at necropsy. ${ }^{12}$ Group analysis showed a significant negative correlation between age and a composite score from six neuropsychological tests, including two tests of visual memory, ${ }^{13}$ in the at risk group but not in their not at risk relatives. With the recent genetic studies showing familial Alzheimer's disease to be a genetically heterogeneous condition, ${ }^{14}$ the methodology of this group study is problematical and the findings tell little about the disease process itself. It, however, marks the first attempt at documenting presymptomatic cognitive impairment in this condition.

The aim of this paper is to report the first longitudinally recorded neuropsychological features of a presymptomatic patient with familial Alzheimer's disease. We present the serial data in the form of an "anatomical map", whereby localised functions are represented according to degree of impairment. At the third assessment only was a clinical diagnosis of familial Alzheimer's disease possible.

\section{Case description}

In 1987 members of the family were referred to the Dementia Research Group by their local medical geneticists. For the purposes of investigation, every family with familial Alzheimer's disease is given a number; every generation within the family a Roman numeral, and every person within the generation a further number. To preserve confidentiality, the family number has not been identified in this paper but is available on written request to bona fide researchers. A neuropsychological study of at risk subjects

Generation

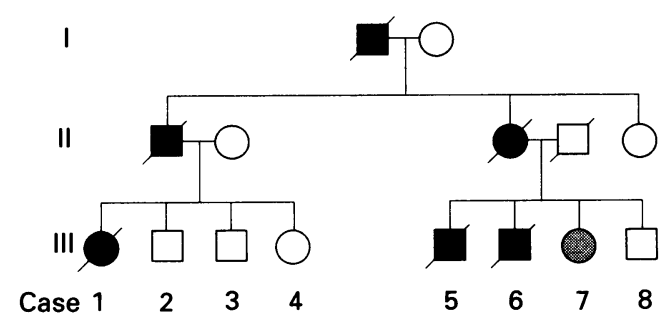

Figure 1 Pedigree. from the familial Alzheimer's disease pedigrees began in 1990. The case we describe, III.7, is represented in the pedigree (fig 1). The pedigree shows a total of six affected deceased people, spanning three generations. Histopathological confirmation of Alzheimer's disease was derived from both cases III. 5 and III.6. The mean age at onset for this family is $45 \cdot 7$ (SD 3.67, range 41-50) years. The family is one of a group that shows linkage to markers on chromosome $14 . .^{15}$

Case III. 7 entered into the at risk neuropsychological study in 1991 when she was 43 years old. This right handed woman left school at the age of 15 . She worked on a factory production line before becoming a housewife; she presently works part time, supervising lunchtime recreation at a local school. A full neurological examination, including the Blessed dementia rating ${ }^{16}$ was performed at the time of the second and third neuropsychological assessments (not performed at the first assessment). On the second assessment she obtained $30 / 30$ on the mini mental state examination (MMSE) ${ }^{17}$ and her neurological examination was entirely normal. On the third assessment she obtained 29/30 on the MMSE and on the Blessed dementia rating (information, concentration subtest) she scored $1 / 5$ on the address recall at five minutes, otherwise performance was normal. This examination also identified subtle muscular twitchings of the fingers, consistent with myoclonus; although there were no primitive reflexes. She made one body-part as object error on a test of ideomotor praxis. At this assessment her husband reported "odd behaviour and memory lapses" while on summer holiday some two months earlier. Case III. 7 was unaware of any change in her abilities over the past seven months. One year later she attended her general practitioner after further instances of memory lapse in daily living.

\section{Methods}

A comprehensive neuropsychological assessment was carried out on three consecutive occasions; 11 July 1991; 11 March 1992; 5 October 1992, with intervals of eight and seven months respectively. A wide range of cognitive functions were investigated; tests included those of language and literacy skills, visuoperceptual, and memory functions. The details of these tests are given in the appendix. The study was approved by the National Hospital ethics committee.

\section{Results of neuropsychological investigations} GENERAL INTELLECTUAL FUNCTION

A shortened version of the WAIS-R was given and verbal and performance IQ measures were obtained by pro-rating seven subtest scores. Table 1 shows these together with the individually weighted scaled scores, corrected for age, for each assessment. Initially case III. 7 was functioning at a dull average level on both verbal and non-verbal scales. This marks 
Table 1 General intellectual test results

\begin{tabular}{|c|c|c|c|c|c|c|}
\hline & \multicolumn{6}{|c|}{ Assessment } \\
\hline & \multicolumn{2}{|l|}{1} & \multicolumn{2}{|l|}{2} & \multicolumn{2}{|l|}{3} \\
\hline & $\begin{array}{l}\text { Test } \\
\text { score }\end{array}$ & $\begin{array}{l}\text { Grade } \\
\text { score }\end{array}$ & $\begin{array}{l}\text { Test } \\
\text { score }\end{array}$ & $\begin{array}{l}\text { Grade } \\
\text { score }\end{array}$ & $\begin{array}{l}\text { Test } \\
\text { score }\end{array}$ & $\begin{array}{l}\text { Grade } \\
\text { score }\end{array}$ \\
\hline \multirow{5}{*}{$\begin{array}{l}\text { Verbal IQ } \\
\text { Subtests: } \\
\text { Digit span } \\
\text { Vocabulary } \\
\text { Arithmetic } \\
\text { Similarities }\end{array}$} & 86 & 3 & 84 & 3 & 82 & 3 \\
\hline & 10 & & 9 & & 8 & \\
\hline & 7 & & 7 & & 7 & \\
\hline & 9 & & 8 & & 7 & \\
\hline & 6 & & 7 & & 6 & \\
\hline \multirow{2}{*}{$\begin{array}{l}\text { Performance IQ } \\
\text { Subtests: }\end{array}$} & 84 & 3 & 83 & 3 & 79 & 3 \\
\hline & & & & & & \\
\hline Picture completion & 8 & & 8 & & 8 & \\
\hline Picture arrangement & 8 & & 6 & & 6 & \\
\hline Block design & 7 & & 9 & & 7 & \\
\hline
\end{tabular}

only a mild deterioration from her optimal level of functioning estimated to have been within the lower limits of the average range (national adult reading test (NART), ${ }^{18}$ educational and occupational histories). Slight further decline was noted in non-verbal skills and the arithmetic and digit span verbal subtests at the third assessment. Despite these subtle changes in performance over 15 months, her full scale IQ remained at a dull average level throughout.

SPECIFIC TESTS OF COGNITIVE FUNCTION

Table 2 gives the raw scores of all specific tests of cognitive function.

\section{Memory function}

The recognition memory test ${ }^{19}$ was used to obtain a measure of verbal (RMW) and visual (RMF) memory functions. On the first test occasion a clear selective verbal memory deficit was present, with an average score on the RMF and a defective score on the RMW. At the second assessment, this discrepancy had diminished; performance on the RMW was at chance and that on the RMF was at a dull average level. Seven months later, both scores were at a defective level.

\section{Language skills}

The graded naming test (GNT) ${ }^{20}$ was given to obtain a measure of nominal skills. The performance of case III $\cdot 7$ remained constant and at an average level across the three test occasions.

\section{Literacy skills}

The assessment of literacy skills comprised individual tests of reading (NART), ${ }^{18}$

Table 2 Results from specific tests of cognition

\begin{tabular}{|c|c|c|c|c|c|c|}
\hline & \multicolumn{6}{|c|}{ Assessment } \\
\hline & \multicolumn{2}{|l|}{1} & \multicolumn{2}{|l|}{2} & \multicolumn{2}{|l|}{3} \\
\hline & $\begin{array}{l}\text { Raw } \\
\text { score }\end{array}$ & $\begin{array}{l}\text { Grade } \\
\text { score }\end{array}$ & $\begin{array}{l}\text { Raw } \\
\text { score }\end{array}$ & $\begin{array}{l}\text { Grade } \\
\text { score }\end{array}$ & $\begin{array}{l}\text { Raw } \\
\text { score }\end{array}$ & $\begin{array}{l}\text { Grade } \\
\text { score }\end{array}$ \\
\hline Speed & 37 & 1 & 34 & 1 & 39 & 1 \\
\hline Arithmetic & 14 & 1 & 14 & 1 & 12 & 1 \\
\hline Spelling & 16 & 2 & 16 & 2 & 13 & 3 \\
\hline NART & 21 & 2 & 22 & 2 & 24 & 1 \\
\hline GNT & 20 & 1 & 19 & 1 & 20 & 1 \\
\hline Silhouettes & 21 & 2 & 19 & 3 & 19 & 3 \\
\hline Cubes & 8 & 3 & 7 & 3 & 5 & 4 \\
\hline RMW & 34 & 5 & 27 & 5 & 29 & 5 \\
\hline $\mathrm{RMF}$ & 44 & 1 & 40 & 3 & 32 & 5 \\
\hline
\end{tabular}

spelling, ${ }^{21}$ and arithmetic. ${ }^{22}$ Case III $\cdot 7$ produced fairly consistent scores on these tests across the test sessions; although on the spelling test her score deteriorated slightly, on the NART and the arithmetic test performance remained at a dull average level.

\section{Perceptual and spatial skills}

Two subtests of the visual object and space perception battery, ${ }^{23}$ silhouettes, and cube analysis (cubes), were used to obtain a measure of perceptual and spatial skills. On the first assessment of case III 7 performance on the silhouettes subtest was within the average range, but on the two subsequent assessments performance had deteriorated slightly, to a dull average level. On the cube analysis subtest performance was within normal limits until the third assessment when her score fell below the 5 th percentile.

\section{Speed and attention}

Cognitive speed and attention were assessed by a digit copying task (speed). ${ }^{24}$ The times (in seconds) obtained by case III. 7 on all three occasions were well within normal limits.

\section{Abstraction}

The Wisconsin card sorting task ${ }^{25}$ was used. On the first assessment her performance was satisfactory; (categories 5; total error score 11; perseverative errors 1 ). On the second and third assessments, however, she failed; obtaining two categories, total error scores of 20 and 18 respectively with only three perseverative errors at each time.

\section{A SCHEMATIC REPRESENTATION FOR} PROGRESSIVE NEUROPSYCHOLOGICAL PROFILES To produce a neuropsychological profile of degenerative disease, it is necessary to compare performances across different cognitive skills. For this purpose we have converted the standardised test performances of all our cases into percentile scores. These scores were then categorised according to five grades: grade score 5 , above or at the 50th percentile; grade score 4 , above or at the 25 th percentile but below the 50th; grade score 3 , above or at the 5 th percentile, but below the 25th; grade score 2 , above or at the 1 st percentile but below the 5th; grade score 1 , below the 1 st percentile. Tables 1 and 2 show case III.7's grade scores, adjacent to their raw score derivatives. Normal scores on the cube analysis subtest of the visual object and space perception battery are not normally distributed as is the case for other tests of cognitive functioning. Control subjects exhibit a ceiling effect on this test and consequently only a pass or fail score, above or below the $5 \%$ cut off point, is appropriate.

To portray levels of cognitive functioning in an anatomically meaningful way, sectors of a circle have been apportioned to each of the cognitive skills examined. A series of concentric circles represents the percentile bands. Hence, levels of individual test performance are indicated by the degree of eccentricity within a sector. The resulting circle diagrams 
Figure 2 Anatomically mapped serial neuropsychological profiles.
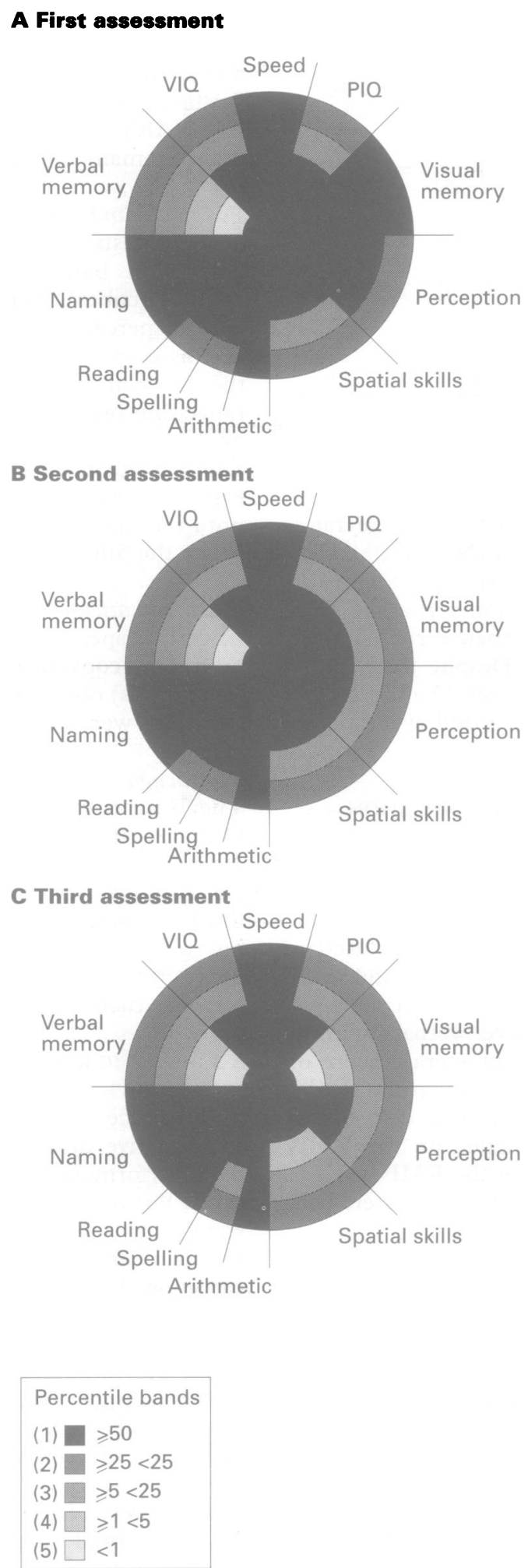

(adapted from $\mathrm{McFie}^{26}$ ) are orientated according to the known localisation of individual cognitive skills, with right and left sides and top and bottom loosely corresponding to the right and left and anterior and posterior regions of the brain. This method produces a neuropsychological "profile map" from which patterns of preserved and affected functioning are quantitatively depicted.

Figure 2 shows the profile maps of case III $\cdot 7$, derived from each neuropsychological assessment session. Figure $2 \mathrm{~A}$ displays the initial presenting, selective verbal memory deficit, in the context of mild general intellectual deterioration and otherwise relatively preserved cognitive functioning. Figures $2 \mathrm{~B}$ and 2C depict the progressive decline in visual recognition memory and, to a lesser extent, in spatial, perceptual, and spelling skills. These profile maps also show naming, reading, arithmetic, and speed and attentional skills as remaining relatively intact.

\section{Discussion}

Figure 2 illustrates evidence of early neuropsychological manifestations in a person with familial Alzheimer's disease confirmed at necropsy. A distinct pattern of impairment was detected, 15 months before abnormalities at neurological examination. The first two assessments of case III $\cdot 7$, therefore, mark presymptomatic cognitive decline of which she, and her family, were entirely unaware.

At the first assessment, the neuropsychological feature of particular note was the grave, selective verbal memory deficit; although there had evidently been a mild deterioration of general intellectual function accompanying this. The localisation power of the recognition memory test ${ }^{19}$ implicates left medial temporal damage in this case. It is also worth noting Warrington's finding that, in cases with diffuse mild bilateral brain atrophy, a selective verbal memory deficit was observed more often than a comparable deficit in the visual domain. ${ }^{19}$ Other studies of mildly affected cases of familial Alzheimer's disease have failed to document a selective memory deficit, partly due to the disease severity in their cases but also because assessments of memory function have given unequal weight to one modality.

The progression of the disease in case III. 7 shows that recognition memory functions become progressively and globally affected relatively quickly (15 month period), implicating progressive bilateral disease. Spatial and perceptual skills deteriorate somewhat across the test occasions in relation to overall language performance. In this context it should be noted that her performance on a stringent naming task remained at an average level. Spelling skills also deteriorated slightly by contrast with other literacy skills which provides support for recent reports of comparatively intact language functioning in affected patients with familial Alzheimer's disease. ${ }^{5}$ This pattern of performance may not be common to all cases of Alzheimer's disease ${ }^{27-29}$ and supports growing evidence of heterogeneous presentations in Alzheimer's disease.

Performance of case III. 7 on the Wisconsin card sorting test also deteriorated significantly, but in the absence of any perseverative errors that would implicate frontal lobe involvement, this could be sensitive to compromised general intellectual function. The inability to obtain the third solution to the task, despite success at a previous test occasion, points to this being the case.

The consistent pattern of intact functioning 
on speed tests, in the light of impaired general intellectual functioning, is an interesting result in that the latter is understood as a general factor of intelligence. Willison ${ }^{30}$ proposes that his speed tasks require attentional factors (maintenance of a mental set) but relatively little cognitive load. We would suggest that in case III 7 the level of intellectual function was compromised but that attentional processes were relatively intact. The discrepant findings of Swearer et $a l^{6}$ and Karlinsky et $a l^{7}$ of decreased cognitive processing speed without intellectual decline early in the disease progression may reflect the differing cognitive demands of the speed tests employed; certainly our finding is classically a feature of cortical, rather than sub-cortical, degenerative conditions. ${ }^{24}$

The difference between case III. 7 and the early affected cases reported by Swearer $e t a l^{6}$ and Karlinsky et $a l,{ }^{7}$ however, may reflect the underlying genetic heterogeneity of familial Alzheimer's disease. Our family is one of eight pedigrees which, as a group, show linkage to markers on chromosome $14,{ }^{15}$ which has been widely reported in early onset familial Alzheimer's disease. ${ }^{31} 32$ By contrast, the family reported by Karlinsky et $a l^{7}$ is associated with the rare APP 717 valine-isoleucine mutation. It remains to be seen whether the early features seen here are specific to chromosome 14 linked familial Alzheimer's disease. Analysis of at risk subjects, however, provides a valuable method of assessing the early features; Winters-Miner et al ${ }^{12}$ were, indeed, correct in their belief that cognitive anomalies can be detected in familial Alzheimer's disease presymptomatically.

Dr MN Rossor is the recipient of an MRC project grant. This work has also been supported by the Barclay Trust, Research into Aging and the Kirkwood Memorial Trust. We are gratefu to Ms Penelope Roques for her help in collecting the family details.

\section{Appendix: descriptions of the tests used WAIS-R}

A shortened version of WAIS-R was given. A verbal and performance IQ was pro-rated from scores on the digit span, vocabulary, arithmetic, and similarities subtests and performance IQ was pro-rated from scores on the picture completion, picture arrangement, and block design subtests.

\section{NATIONAL ADULT READING TEST (NART)}

This national adult reading test, consisting of 50 irregular words was given to provide an estimate of premorbid intelligence and the combined scores were transformed into full scale IQ equivalents.

\section{RECOGNITION MEMORY TEST ${ }^{19}$}

The verbal version of the recognition memory test (RMW) consists of 50 stimulus words. Recognition memory was tested by presenting each of the words paired with a distractor, the subject being required to make a forced choice between them. The raw scores for both versions were converted into age corrected percentile scores. The visual version of this test (RMF) consists of 50 black and white photographs of unfamiliar male faces. The subject was asked to recognise them when each was paired with a distractor photograph drawn from a similar pool.

\section{GRADED NAMING TEST [GNT] ${ }^{20}$}

The object naming test of graded difficulty consists of 30 black and white line drawings. The number of objects correctly named was converted into an equivalent vocabulary percentile score.

\section{SPELLING TEST ${ }^{21}$}

The oral spelling test consists of 30 irregularly spelt words, graded in difficulty. The raw scores convert into percentile scores.

\section{ARITHMETIC TEST ${ }^{22}$}

The test of oral arithmetic consists of 12 graded difficulty additions and 12 graded difficulty subtractions. A 10 second time limit is imposed for each sum, after which the answer is not scored. The raw score was converted into a percentile score.

\section{VISUAL OBJECT AND SPACE PERCEPTION BATTERY ${ }^{23}$}

The silhouettes subtest consists of 15 animal and 15 object stimuli. This graded difficulty test comprises black silhouettes of each item rotated through varying degrees from the lateral axis. The standard procedures were followed. The raw scores were converted to percentile scores. The cube analysis subtest is a graded difficulty test of visuospatial skills and consists of 12 black outline representations of three dimensional arrangements of square bricks. Subjects have to count the number of cubes in the structures according to standard administration. The raw scores were recorded as a pass or fail using a $5 \%$ cut off.

DIGIT COPYING SPEED TEST ${ }^{24}$

The digit copying speed test consists of rows of randomly assorted single digits, which the subject has to copy in his or her own hand writing. The responses are timed and these converted into percentile scores.

WISCONSIN CARD SORTING TEST (MODIFIED) ${ }^{25}$ The Wisconsin card sorting test is an abstraction in which subjects have to sort cards on which different numbers and colours of four different shapes appear. The manner in which the cards are sorted is determined by the examiner and changes after every six cards correctly positioned. Numbers of errors are recorded along with the number of repeated wrong answers-perseverations and the number of categories obtained. The result is recorded as a pass or fail.

\footnotetext{
1 McKhann G, Drachman D, Folstein M, et al. Clinical diagnosis of Alzheimer's disease: report of the NINCDS-ADRDA Work Group under the auspices of Department of Health and Human Services Task Force on Alzheimer's disease. Neurology 1984;34:939-44.

2 Katzman R, Aronson M, Fuld P, et al. Development of a dementing illness in an 80 year old volunteer cohort.
} Ann Neurol 1989;23:138-44. 
3 Cutler N, Haxby J, Duara R, et al. Brain metabolism as measured with positron emission tomography: Serial Neurology 1985;35:1556-61.

4 Sadovnick A, Tuokko $\mathrm{H}$, Horton A, et al. Familial

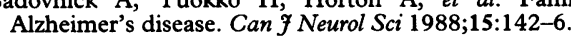

5 Kennedy A, Newman S, McCaddon A, et al. Familial Kennedy A, Newman S, McCaddon A, et al. Familial Alzheimer's disease: A pedigree with a mis-sense mutation in the amyloid precursor protein gene (amyloid pre-
curson protein 717 valine-glycine). Brain 1993;116: 309-24.

6 Swearer J, O'Donnell B, Drachman D, Woodward B. Neuropsychological features of familial Alzheimer's disease. Ann Neurol 1992;32:687-94

7 Karlinsky H, Vaula G, Haines J, et al. Molecular and prospective phenotypic characterisation of a pedigree with familial Alzheimer's disease and a mis-sense mutation in codon 717 of the $\beta$-amyloid precursor protein. Neurology 1992;42:1445-53.

8 Van Duijn C, Broeckhoven C, Hardy J, et al. Evidence for allelic heterogeneity in familial early-onset Alzheimer's disease. Br F Psychiatry 1991;158:471-4.

9 Bennett T, Curiel M. Early neuropsychological presentation of Huntington's disease. Int $\mathcal{f}$ Clin Neuropsychol 1989;11:90-5.

10 Hefter J, Homberg V, Lange H, Freund H-J. Impairment of rapid movement in Huntington's disease. Brain 1987; 110:585-612.

11 Polinsky R, Noble, H, Di Chiro G, et al. Dominantly Inherited Alzheimer's disease: cerebral glucose metabolism. I Neurol Neurosurg Psychiatry 1987;50:752-7.

12 Winters-Miner L, Stryker D, Burgus R, Miner G. The search for possible neuropsychological associations and other markers in familial Alzheimer's disease. In: Miner G, Richer R, Blan J, et al, eds. Familial Alzheimer's disease: molecular genetics and clinical perspectives. New York: Marcel Dekker Inc, 1989:203-22.

13 Benton A, Hamsher K, Varney N, Spreen O. Contributions to neuropsychological assessment. New York: Oxford to neuropsychological asses

14 Rossor MN. Molecular pathology of Alzheimer's disease. $\mathcal{F}$ Neurol Neurosurg Psychiatry 1993;56:583-6.

15 Mullan 1 . familial early onset Alzheimer's disease on the long arm of chromosome 14, proximal to the 1-antichymotrypsin gene. Nature genetics 1992;2:340-2.

16 Blessed G, Tomlinson B, Roth $M$. The association between quantitative measures of dementia and of senile change in the grey matter of elderly subjects. $\mathrm{Br} \mathcal{F}$ Psychiatry 1968;114:797-811.

17 Folstein M, Folstein S, McHugh P. Mini-mental state: A practical method for grading the mental state of patients practical method for grading the mental state of
for the clinician. $\mathcal{F}$ Psychiatr Res 1975;12:189-98.

18 Nor the clinician. $f$ Psychiatr Res $1975 ; 12: 189-98.2$. Windsor: NFER Nelson Publishing Co, 1991.

19 Warrington EK. The recognition memory test. Windsor: Warrington EK. The recognition memor
NFER Nelson Publishing Co, 1984.

20 McKenna P, Warrington EK. The graded naming test. Windsor: NFER Nelson Publishing Co, 1983.

21 Baxter D. Acquired spelling disorders. London: University of London, 1987. (PhD thesis.)

22 Jackson M, Warrington EK. Arithmetic skills in patients with unilateral lesions. Cortex 1986;22:611-20.

23 Warrington EK, James M. The Visual object and space perception battery. Bury St Edmunds: Thames Valley Test Company, 1991

24 Willison J, Warrington EK. Cognitive retardation in a patient with preservation of psychomotor speed. Behav Neurol 1992;5:113-6.

25 Nelson $H$ A modified card sorting test sensitive to frontal lobe defects. Cortex 1976;12:313-24.

26 McFie J. Assessment of organic intellectual impairment. New York: Academic Press, 1975.

27 Appell J, Kertesz A, Fisman MA. Study of language functioning in Alzheimer's disease. Brain and Language 1982;17:73-91.

28 Kirshner $H$, Webb W, Kelly $M$. The naming disorder of dementia. Neuropsychologia 1984;22:23-30.

29 Cummings J, Benson F, Hill M, Read S. Aphasia in dementia of the Alzheimer type. Neurology 1985;35: 394-7.

30 Willison J. Neuropsychological Investigations of a set of mental speed tests. London: University of London, 1987. (PhD thesis.)

31 St George Hyslop P, Haines J, Mortilla M, et al. Genetic evidence for a novel familial Alzheimer's disease locus on chromosome 14. Nature genetics 1992;2:330-4.

32 Broeckhoven C, Backhovens H, Cruts M, et al. Mapping of a gene predisposing to early onset Alzheimer's disease of a gene predisposing to early onset Alzheimer's disease
to chromosome 14q24.3. Nature Genetics 1992;2:335-9. 